\title{
TEXTURE ASYMMETRIES AS SHEAR SENSE INDICATORS IN NATURALLY DEFORMED MONO- AND POLYPHASE CARBONATE ROCKS
}

\author{
B. LEISS*, S. SIEGESMUND and K. WEBER \\ Institut für Geologie und Dynamik der Lithosphäre (IGDL), Universität \\ Göttingen, Goldschmidtstr. 3, D-37077 Göttingen, Germany
}

The microstructural and quantitative texture analyses of a naturally deformed calcite mylonite, a dolomite mylonite and a dolomitic calcite mylonite reveal different texture asymmetries for comparable deformation conditions. Calcite shows a $c$-axis maximum rotated against the shear sense with regard to the main shear plane. In contrast, the dolomite shows a $c$-axis maximum rotated with the shear sense. In accordance with the experimental and simulated textures from the literature, this difference proves e-twinning and r-slip for calcite and f-twinning and c-slip for dolomite as the main deformation mechanisms. The dolomitic calcite mylonite shows for both the calcite and the dolomite a $c$-axis maximum rotated against the shear sense. On account of the microstructure of this sample, the dolomite texture has been passively overtaken from the deformation texture of calcite during a late-deformative dolomitization. The results significantly contribute to the interpretation that the sampled shear zone is a transpressive strike-slip fault.

Keywords: Quantitative texture analysis; Polyphase carbonates; Texture asymmetry; Shear sense indicator; Deformation history

\section{INTRODUCTION AND SCOPE}

In geology, one of the important applications of texture analyses is the unravelling of the deformation history and the kinematics of mountain building processes. For this purpose, the texture types and the texture

\footnotetext{
* Corresponding author. Tel.: +49/551/39-7934. Fax: +49/551/39-9700. E-mail: bleiss1@gwdg.de.
} 
symmetries are geometrically correlated with the structural framework, i.e. the foliation, the lineation, the fold axes or a grain shape preferred orientation. Whether and to what extent the symmetry of the fabric or texture of deformed rocks can reflect the symmetry of the deformation kinematics is still under discussion. Coaxial deformation produces fabrics and textures that are symmetric with respect to the principal axis of finite strain, whereas non-coaxial deformation tends to produce asymmetric fabrics. Moreover, distinguishing between coaxial and noncoaxial deformation requires, in the case of polyphase deformation, knowledge about the deformation history. While the bulk fabric and texture result from the polyphase deformation, deformation increments may be inferred from different subfabrics. These kind of studies are limited by the fact that in a complex deformation history the initial or early formed fabrics may be overprinted by fabrics which preferentially reflect the latest deformation increment and the related conditions. This shows that in nature the deformation history is heterogenous in space and time. Therefore, the interpretation of fabric and texture asymmetries also strongly depends on the chosen reference frame like shear zone boundaries or fold geometries.

Generally, monophase rocks are the more favoured candidates for such investigations because their texture is much easier to determine. Also the interpretation of the data is easier because intermineralic reactions and the mutual influence of different mineral phases on the texture development can be excluded. Moreover, in nature monophase rocks are the exception, while most of the rocks are polyphase, composed of three or more mineral phases. Accordingly, structural geologists have a high interest in the texture analysis of polyphase rocks and its interpretation.

Neutron texture analysis has already been demonstrated as a successful tool for the texture analysis of polyphase rocks (e.g. Wenk and Pannetier, 1990; Leiss et al., 1994; Siegesmund et al., 1994; Ullemeyer et al., 1994). This study focuses on the interpretation of such neutron textures of a dolomitic calcite mylonite by comparing the textures of the two mineral phases with the textures of corresponding monophase dolomite and calcite mylonites, which developed at the same deformation conditions. Carbonate phases meet the requirements for such comparisons particularly well due to their relative high and similar trigonal crystallography (calcite: $\overline{3} \mathrm{~m}$, dolomite: $\overline{3}$ ) and because they can 
be found next to each other as mono- and polyphase rocks. Although a large number of samples were measured (see also Leiss, 1996), this paper focuses on a few representative samples in order to summarize the characteristics of the shear-sense related texture asymmetries of calcite and dolomite.

\section{ORIGIN OF THE SAMPLES}

A series of mono- and polyphase rocks was collected in the Saagbergshear zone within the Southwestern Margin Zone of the Damara Orogen in Namibia. The steeply west-dipping Saagberg-shear zone of about $50 \mathrm{~m}$ thickness is located at the eastern slopes of the N-S striking Saagberg Mountains in the north of the settlement of Solitaire (refer to the geological map of Raab, 1995). The carbonate sequence within the shear zone consists mainly of bright and dark grey dolomite mylonites and some quartz-interlayers. Mylonites are rocks which have been deformed by a combination of intracrystalline slip and dynamic recrystallization leading to grain-size reduction. At the southwestern margin of the Damara Orogen, deformation took place under the metamorphic conditions of the Upper Greenschist Facies (about $500^{\circ} \mathrm{C}$ ). Unfortunately, a layer of monophase calcite could not be found in this shear zone. Alternatively, a calcite mylonite was collected from a comparable shear zone at the closely located Witberg Mountains (Leiss, 1996).

\section{EXPERIMENTAL SETUP}

The monophase, fine-grained dolomite-mylonite was measured on a $\mathrm{X}$-ray goniometer in reflection mode. Circular and polished sections were used to determine the pole density distribution of the (006)-, (110)-, (104)-, (012)- and (015)-reflections. The measuring points are arranged on a spiral. After background subtraction, the defocusing effect was corrected with a polynom derived from a powder measurement (Ullemeyer and Weber, 1994). Due to a high error at large tilt-angles, the data for tilt angles $>75^{\circ}$ were neglected. To obtain complete pole figures, the measurements of three mutually perpendicular sections were combined. 
Due to the large grain size of calcite (also in the mylonites), the low volume fraction of dolomite and the peak-overlap due to the polyphase composition, the textures of the other samples were measured by means of the high resolution time-of-flight neutron diffractometer NSHR in Dubna (Helming et al., 1992; Walther et al., 1995). Spherical samples with a volume of about $14 \mathrm{~cm}^{3}$ were used to obtain good counting statistics. Measuring conditions were the same as already described by Leiss et al. (1994). To save measuring time, the experimental pole figures were incompletely measured. However, due to the large number of measured pole figures, the preconditions for a quantitative texture analysis were met (Helming, 1992).

On the basis of these $\mathrm{X}$-ray and neutron pole figures, the quantitative texture analyses were carried out by means of component deconvolution (e.g. Helming and Eschner, 1990; Helming et al., 1994).

\section{RESULTS: GRAIN FABRICS AND TEXTURES}

All thin section photo micrographs and pole figures are presented in a consistent reference frame. They are all oriented perpendicular to the main foliation/compositional layering and parallel to the stretching lineation (indicated in all figures).

\subsection{Calcite Mylonite}

Locally, the polyphase deformed, dark grey calcite mylonite contains mica up to $15 \%$, whereas the sample investigated contains less than $5 \%$ mica. As accessories, a few ore-, quartz- and plagioclase-grains were observed.

The relatively large calcite grains are elongated with an aspect ratio of the grain short/long axis up to $1: 5$ (Fig. 1(a)). In average, the long axes measure from 0.7 to $1.5 \mathrm{~mm}$ and are preferentially oriented at an angle of about $30^{\circ}$ with respect to the main foliation. Such a so-called "oblique grain shape fabric" allows one to derive the shear sense (in this case top to the left). Since undulous extinction is missing and twinned grains are rare, the partly straight grain boundaries as well as triple junctions of the grain boundaries indicate a late-deformative recovery. 


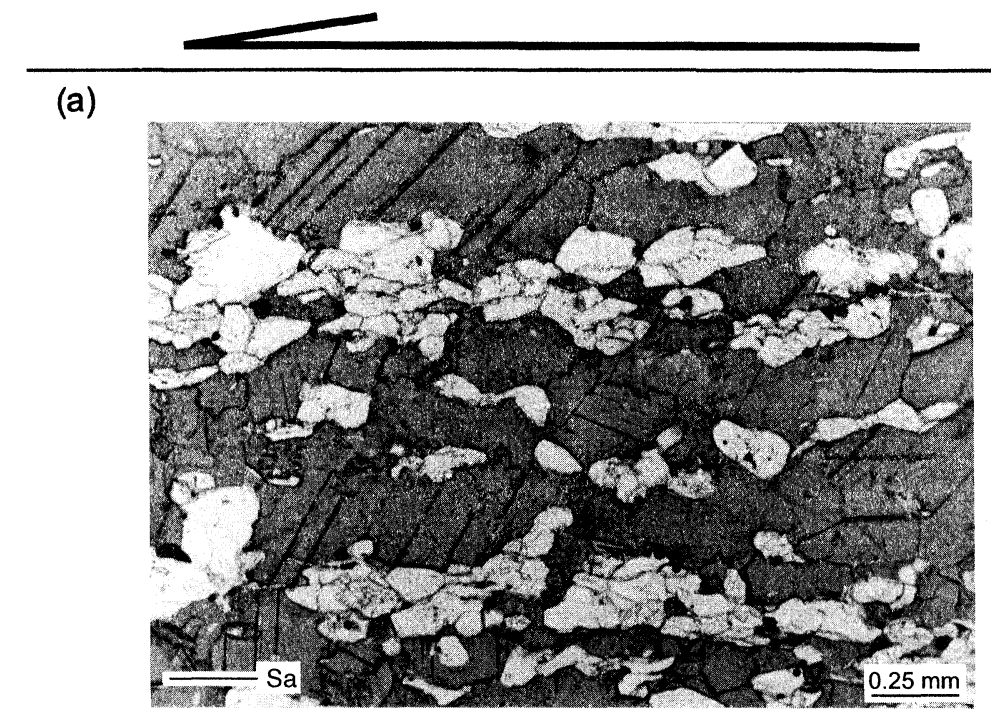

(b)

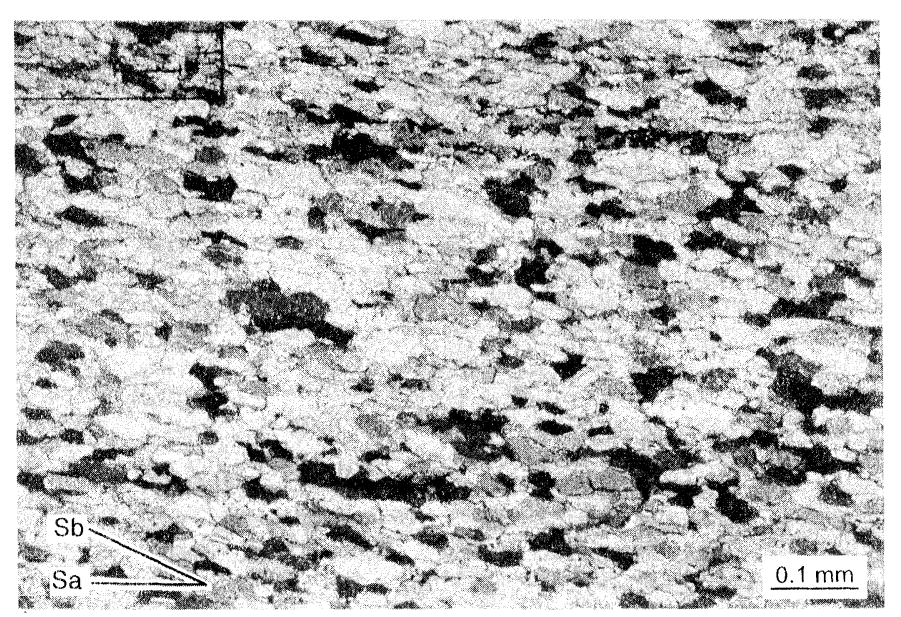

FIGURE 1(a) and (b) 


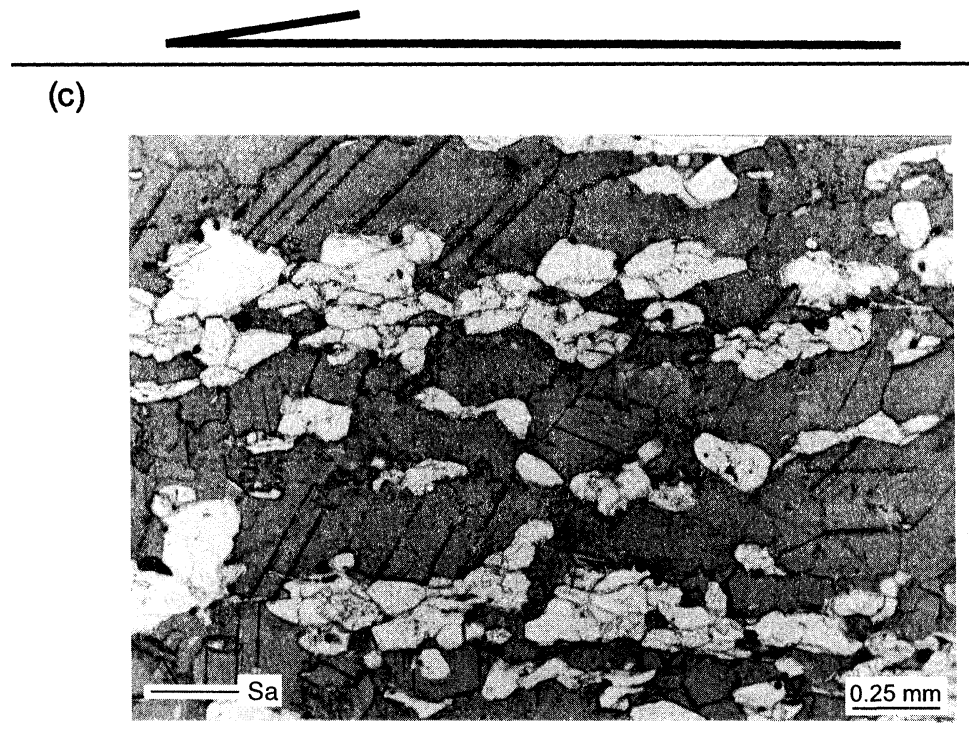

FIGURE 1(c)

FIGURE 1 Photomicrographs of thin sections of the (a) calcite mylonite (cross polarized light), (b) dolomite mylonite (cross polarized light), (c) dolomitic calcite mylonite, calcite $=$ dark, dyed with AlizarinS, dolomite and accessories $=$ bright (plane polarized light). Sa: main foliation, Sb: subordinate foliation defined by the preferred grain shape orientation of the matrix.

However, it is not expected that this process influences the texture significantly (see Rutter et al., 1994).

The mica grains, up to $1 \mathrm{~mm}$ in length, are aligned parallel to the long axes of the calcite grains.

Due to the large grain size of the sample, neutron texture goniometry was applied. The basic texture component of this sample is a fibre texture (Fig. 2(a)) with the fibre axis (indicated in Fig. 2(a)) parallel to the preferred $c$-axes orientation (" $c$-axis fibre type", see Leiss, 1996; Leiss et al., 1996). Some minor components form a maxima within the $a$-axis girdle and the incomplete small circles of the normals to the rhombohedrons and the f-twin planes. With respect to the reference frame, the $c$-axis pole figure shows a maximum rotated against the shear 


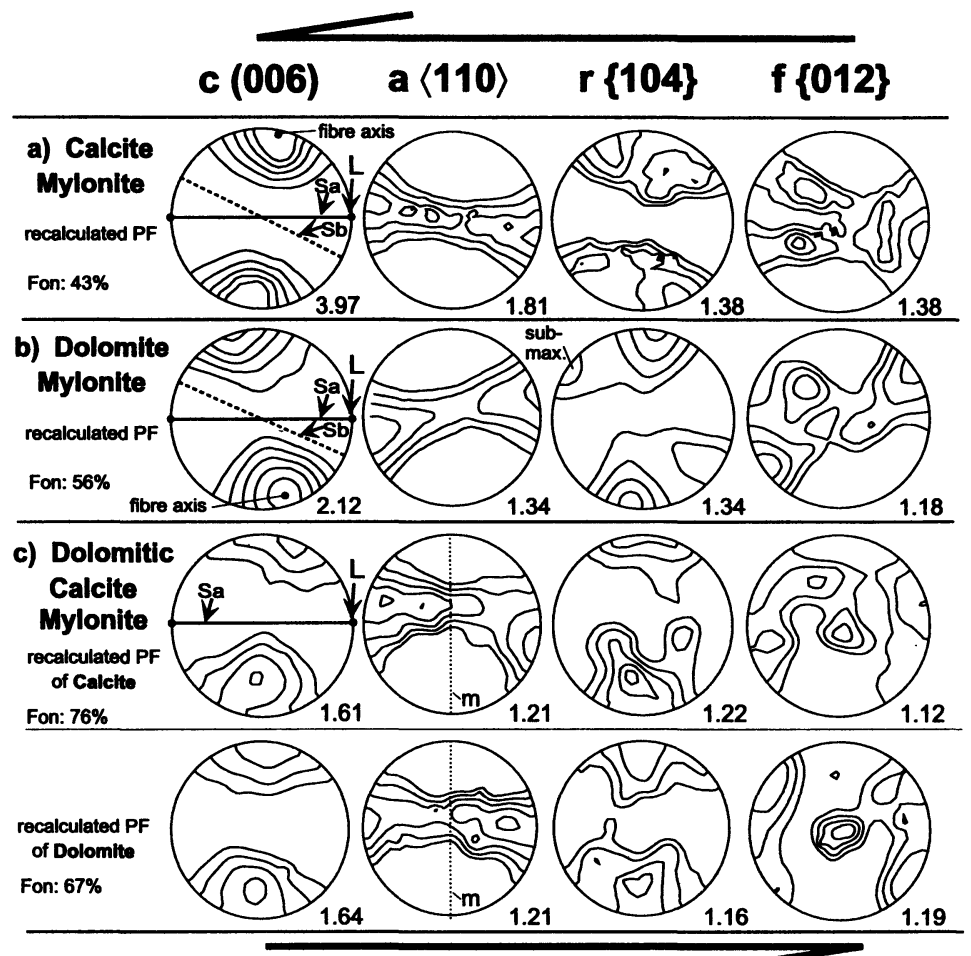

FIGURE 2 Textures of the three samples investigated (lower hemisphere, stereographic projection, lowest contour equal to one times random. The relative maxima are indicated. $\mathrm{Sa}$ : main foliation, $\mathrm{Sb}$ : subordinate foliation defined by the preferred grain shape orientation of the matrix, m: mirror plane, Fon: random part of the texture).

sense. The position of the $a$-axis maximum, inclined adequately to the $c$-axis maximum with respect to the stretching lineation, confirms a shear direction parallel to the stretching lineation.

\subsection{Dolomite Mylonite}

The homogenous, dark grey dolomite mylonite also reveals an oblique grain shape fabric enclosing an angle of about $25^{\circ}$ between the main shear plane and the preferred oriented grain long axes (Fig. 2(b)). In contrast to the first sample, the grain long axes measure only about $0.05-0.1 \mathrm{~mm}$ with a short/long grain axis ratio of only about $1: 2$. Such a fine-grained mylonitic dolomite fabric is typical for the investigated 
region. Again, the shear sense derived from this oblique grain shape fabric is in accordance with other shear-sense indicators of the Saagberg-shear zone.

The texture analysis of this sample is based on X-ray pole figures. In comparison with the calcite mylonite, this sample also reveals a $c$-axis fibre type (Fig. 2(b)). The $a$-axes also form a maximum within the girdle indicating shear parallel to the stretching lineation. In contrast to the calcite texture, the normals to the rhombohedral planes do not exhibit a small circle distribution, but a stronger single maximum and the typical weak submaximum. The crucial difference, however, is the rotation of the fibre axis with the shear sense (synthetically) and not against the shear sense (antithetically) as in the case of calcite.

\subsection{Dolomitic Calcite Mylonite}

This yellowish homogenous sample consists of calcite and dolomite with an estimated ratio of $7: 1$. There are also some percentages of quartz and accessory muscovite, plagioclase and ore minerals. The microscopic grain fabric reveals a distinct bimodal grain-size distribution with large calcite and small dolomite grains. This is especially obvious in the section parallel to the lineation/perpendicular to the foliation because in this section the calcite grains are distinctly elongated. The calcite grains are elongated up to a ratio of $1: 5$ and the grain long axes possess a length up to $1.3 \mathrm{~mm}$. The grain long axes of calcite are aligned parallel to the lineation. There is no obvious oblique grain shape fabric for calcite or dolomite. Some calcite grains are twinned. The dolomite is only weakly elongated up to an axes ratio of $1: 2$ with a maximum length of the long axis of about $0.2 \mathrm{~mm}$. In contrast to the calcite, the alignment of the long axes parallel to the lineation is less pronounced. The small dolomite grains surround most of the large calcite grains in thin layers, but are more frequent in layers parallel to the foliation. The grain boundaries of calcite are interlobate or ameoboid and frequently enclose the dolomite grains nearly completely. In the section perpendicular to the lineation and perpendicular to the foliaton, no significant grain shape anisotropy can be observed.

The quantitative texture analysis is based on neutron pole figures, which were extracted from the time-of-flight spectra (Fig. 3). The textures of both mineral phases are quite weak but significant. Both textures are 


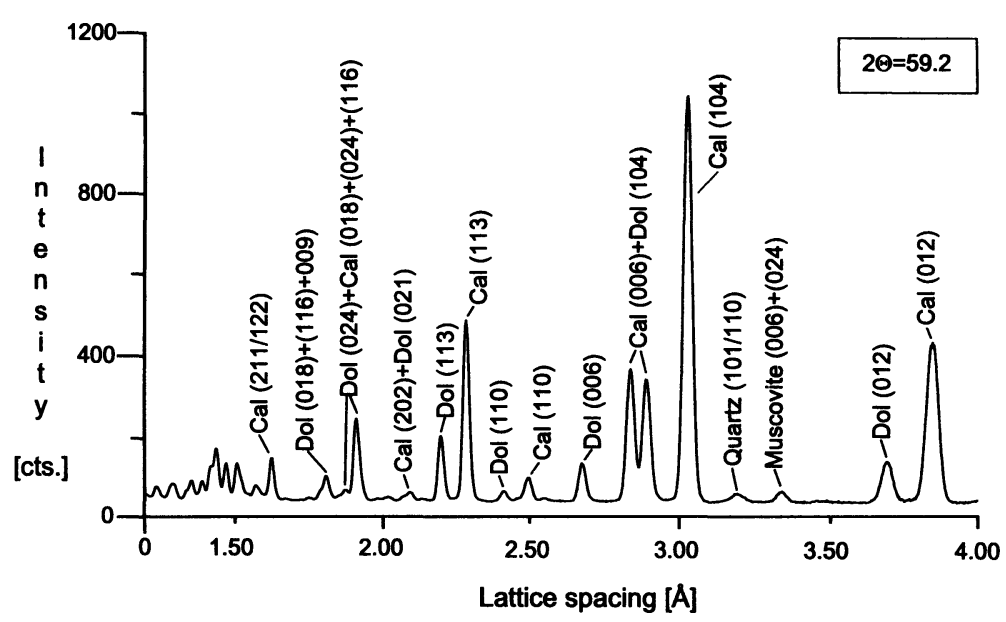

FIGURE 3 Averaged summation of all spectra at $2 \Theta=59.2$ for the dolomitic calcite mylonite (normalized with respect to the energy distribution). All the indexed reflections of dolomite and calcite were used for the quantitative texture analysis (see text).

again of the $c$-axis fibre-type showing the same orientation of the fibre axes (Fig. 2(c)). However, a much better match can be seen by a mirroring of the pole figures at a reflection plane as indicated in Fig. 2(c). The most interesting feature is that the fibre axis of the dolomite texture is rotated against the shear sense. The calcite phase obviously controls the texture development and the texture of dolomite seems to be passively adopted to the calcite texture. Another remarkable feature of the texture is that the $c$-axis maxima are not only rotated against the shear sense, but they are also significantly rotated out of the projection plane of the pole figures.

\section{DISCUSSION}

\subsection{Texture Forming Mechanisms and the Related Texture Asymmetries}

Considering the grain shape fabric and the orientation relation between the analysed textures with regard to fabric elements like the stretching lineation, the foliation and the grain shape preferred orientation, it is obvious that the textures are deformation-induced. Furthermore, from the preferred grain shape fabrics it is obvious that intracrystalline slip is one of the dominating deformation mechanisms. These conclusions 
may be verfied by comparing the results with experimentally or numerically generated textures.

A lot of work has been done in the past to investigate the deformational behaviour of calcite (e.g. Schmid et al., 1987; Wenk et al., 1987; Rutter et al., 1994). A recent overview is given by LaFrance et al. (1994), which helps to keep this discussion restricted to the main basic points. Unfortunately, most of these authors present only $c$-axis pole figures which makes a refined comparison difficult. The simple-shear-deformation experiments of Friedmann and Higgs (1981), Kern and Wenk (1983) and Schmid et al. (1987) reveal three different texture types, which can be related to the dominating deformation mechanism. Twinning causes a distinct single maximum rotated against the shear sense. Intracrystalline slip causes two main maxima. One maximum approximately parallels the foliation normal and the other maximum is rotated against the shear sense. For grain boundary migration as the dominating deformation mechanism, Friedmann and Higgs (1981) found a maximum, which is clearly rotated with the shear sense, whereas Schmid et al. (1987) found the opposite shear sense. Numerical texture modelling by Wenk et al. (1987) with twinning and intracrystalline slip as the main deformation mechanisms produced a rotation of the $c$-axis maxima against the shear sense. This supports the fact that the calcite texture presented in this paper developed by e-twinning and intracrystalline slip (dominated by r-slip) under low temperature conditions. No texture modification by recovery processes is obvious. This is in agreement with the experimental observations of Rutter et al. (1994).

For dolomite there exist a number of published deformation experiments (e.g. Barber et al., 1994); however, they are generally restricted to axisymmetric deformation regimes. Therefore, they cannot explain texture asymmetries which originated from a simple shear deformation. Numerically texture simulations were performed by Leiss and Helming (1996) for different deformation regimes, numerical models and temperature ranges. The modelled texture type for a simple shear regime under low temperature conditions coincides very well with the texture of the dolomite mylonite. 'Low temperature' corresponds to $200^{\circ} \mathrm{C}$ with c-slip in $\langle a\rangle$ and f-twinning as the dominant deformation mechanisms. The only but crucial difference between the textures is that the fibre axis of the modelled texture is oriented perpendicular to the foliation and not rotated with the shear sense. If the texture is related to the crystallographic reference frame, the texture shows an asymmetry 
itself, which is attributed to the twinning. Even such details are in agreement between what is observed in natural and simulated textures. The asymmetry would suggest a rotation against the shear sense. This finding might be explained by the idea that the main foliation is not the active shear plane.

In the dolomitic calcite mylonite, the calcite texture and its asymmetry according to the coordinate system are in a very good agreement with the texture of the monophase calcite mylonite. It is obvious that the same deformation mechanisms produced similar textures in both samples. This is not likely for the dolomite. Although the texture is in a good agreement with the texture of the monophase dolomite mylonite, the fibre axis is oriented in a way like the calcite. This feature and the good similarity with the calcite texture type suggest that the dolomite inherited the texture from the calcite. This idea is supported by the grain fabric. The large calcite grains may be dolomitized at the grain boundaries. During that dolomitization, the orientation of the new grains did not change significantly. More information on the texture development of the dolomitic calcite mylonite may be obtained by the investigation of the grain-to-grain orientation relationships by single grain orientation determinations by means of electron backscatter patterns (e.g. Lloyd and Freeman, 1991; Kunze et al., 1994), and by having a closer look at the local chemical composition of the fabric (e.g. with cathodoluminescence) to find indications for the processes which occurred during phase transition.

Such a close geometrical relationship between the textures of the dolomitic calcite mylonite as described here is completely different from the findings in the calcitic dolomite mylonites described by Leiss $e t$ al. (1994). Those calcite and dolomite textures show no recognizable geometrical relationship. Therefore it is unlikely that the close relationship of the textures found in this paper is attributed to the measurements or the data processing.

\subsection{Geological Significance}

The grain fabric and texture analyses support the model of the Saagberg-shear zone which represents a sinistral strike-slip fault (Raab, 1995). In this context, an additional feature of the textures is of interest. Both samples from the Saagberg-shear zone exhibit an additional inclination of the fibre axis with respect to the projection plane of 
the pole figures. Such a feature points to a transpressive deformation regime which was already recognized from the field data (Raab, 1995). The development of such "oblique" textures and transpressive deformation regimes are described in more detail by Ullemeyer and Weber (1999). Considering this additional information, the textures will help to unravel the structural development in more detail in the future, especially in view of the time-related development of geological structures (deformation history).

\section{SUMMARIZED CONCLUSIONS}

- Despite their similar crystallography, monophase calcite and dolomite mylonites reveal different texture asymmetries in a simple shear deformation regime. In calcite the $c$-axis maximum is rotated against the shear sense in regard to the main shear plane; in dolomite the $c$-axis maximum is rotated with the shear sense. This variation is explained by the activation of different twin and intracrystalline slipsystems due to their different critical resolved shear stresses.

- In the dolomitic calcite mylonite, both the textures of calcite and dolomite reveal a texture asymmetry as observed for the monophase calcite mylonite. The grain fabric supports the idea, that the calcite grains were marginally dolomitized during the late stages of deformation and that the dolomite inherited the earlier produced deformation texture from the calcite phase.

- Although a lot of experimental and numerical work on the development of deformation textures of calcite and dolomite can be found in the literature, not all the features of the textures can be explained in naturally deformed carbonates, especially such detailed features which are revealed by a quantitative texture analysis. Much more systematic and detailed work has to be done on the natural development of textures in carbonates, because they can be an important kinematic indicator in the study of deformation histories. This is especially true for polyphase carbonates.

\section{Acknowledgments}

Klaus Ullemeyer is thanked for his constructive comments which helped to improve the manuscript. This research was financially supported by 
the Deutsche Forschungsgemeinschaft (Si 438/5-1) and the Deutsche Bundesministerium für Bildung, Wissenschaft, Forschung und Technologie (03-DUBGOE1-7). B.L. is grateful for the support he received from a DFG-postdoc-fellowship.

\section{References}

Barber, D.J., Wenk, H.-R. and Heard, H.C. (1994). The plastic deformation of polycrystalline dolomite: comparison of experimental results with theoretical predictions. J. Mater. Sci. \& Eng. 175, 83-104.

Friedmann, M. and Higgs, N.G. (1981). Calcite fabrics in experimental shear zones. In: Mechanical Behaviour of Crustal Rocks, Eds. N.L. Carter, M. Friedmann, J.M. Logan and D.W. Stearns, Am. Geophys. Union, Geophys. Monogr. 24, 11-27.

Helming, K. (1992). Minimal pole figure ranges for quantitative texture analysis. Textures and Microstructures 19, 45-54.

Helming, K. and Eschner, T. (1990). A new approach to texture analysis of multiphase materials using a texture component model. Cryst. Res. Technol. 25, K203-K208.

Helming, K., Voitus, W. and Walther, K. (1992). Progress in texture investigations at the pulsed reactor IBR-2. Physica B 180 \& 181, 1025-1028.

Helming, K., Wenk, H.-R., Choi, C.S. and Schäfer, W. (1994). Description of quartz textures by components. Examples from metamorphic rocks. In: "Textures of Geological Materials", Eds. H.J. Bunge, S. Siegesmund, W. Skrotzki and K. Weber, pp. 303-326. Oberursel: DGM-Press.

Kern, H. and Wenk, H.-R. (1983). Calcite texture development in experimentally induced ductile shear zones. Contrib. Mineral Petrol 83, 231-236.

Kunze, K., Heidelbach, F., Wenk, H.-R. and Adams, B.L. (1994). Orientation Imaging Microscopy of Calcite Rocks. In: "Textures of Geological Materials", Eds. H.J. Bunge, S. Siegesmund, W. Skrotzki and K. Weber, pp. 127-146. Oberursel: DGMPress.

LaFrance, B., White, J.C. and Williams, P.F. (1994). Natural calcite $c$-axis fabrics: an alternate interpretation. Tectonophysics 229, 1-18.

Leiss, B. (1996). Strukturbezogene Textur- und Korngefügeuntersuchungen duktil deformierter Dolomitgesteine am Südwestrand des Damara Orogens (Namibia) Mechanismen der Texturbildung und ihre kinematische Bedeutung. Geotekt. Forsch. 84, 130.

Leiss, B., Siegesmund, S., Weber, K. and Olesen, N.Ø. (1994). Localized texture components of a naturally deformed dolomite - a contribution to the analysis of textureforming processes. In: "Textures of Geological Materials", Eds. H.J. Bunge, S. Siegesmund, W. Skrotzki and K. Weber, pp. 261-275. Oberursel: DGM-Press.

Leiss, B. and Helming, K. (1996). Natural and simulated textures for the analysis of natural deformation paths. Proceed. Eleventh Int. Conf. Textures of Materials, pp. $1275-1280$.

Leiss, B., Siegesmund, S. and Weber, K. (1996). The development of different texturetypes in ductile deformed dolomite rocks. Int. Geol. Congr. Beijing. 265.

Lloyd, G.E. and Freeman, B. (1991). SEM electron channeling analysis of dynamic recrystallization in a quartz grain. J. Struct. Geol. 13, 945-953.

Raab, M. (1995). Kartierbericht zur Geologischen Karte des Saagbergs am Südrand des Damara-Orogens/Namibia. Unpublished Diploma-thesis, University of Göttingen, pp. 41.

Rutter, E.H., Casey, M. and Burlini, L. (1994). Preferred crystallographic orientation development during the plastic and superplastic flow of calcite rocks. J. Struct. Geol. 16, 1431-1446. 
Schmid, S.M., Panozzo, R. and Bauer, S. (1987). Simple shear experiments on calcite rocks: rheology and microfabric. J. Struct. Geol. 9, 747-778.

Siegesmund, S., Helming, K. and Kruse, R. (1994). Complete texture analysis of a deformed amphibolite: comparison between neutron diffraction and $U$-stage data. J. Struct. Geol. 16, 131-142.

Ullemeyer, K. and Weber, K. (1999). Lattice preferred orientation as an indicator of a complex deformation history of rocks. Textures and Microstructures 33, 45-60.

Ullemeyer, K. and Weber, K. (1994). Correction of phyllosilicate (002) X-ray pole figure measurements. In: "Textures of Geological Materials", Eds. H.J. Bunge, S. Siegesmund, W. Skrotzki and K. Weber, pp. 83-92. Oberursel: DGM-Press.

Ullemeyer, K., Helming, K. and Siegesmund, S. (1994). Quantitative texture analysis of plagioclase. In: “Textures of Geological Materials", Eds. H.J. Bunge, S. Siegesmund, W. Skrotzki and K. Weber, pp. 93-108. Oberursel: DGM-Press.

Walther, K., Heinitz, J., Ullemeyer, K., Betzl, M. and Wenk, H.-R. (1995). Time-of-flight texture analysis of limestone standard: Dubna results. J. Appl. Cryst. 28, 503-507.

Wenk, H.R., Takeshita, T., Bechler, E., Erskine, B.G. and Matthies, S. (1987). Pure shear and simple shear on calcite textures. Comparison of experimental, theoretical and natural data. J. Struct. Geol. 9, 731-745.

Wenk, H.-R. and Pannetier, J. (1990). Texture development in deformed granodiorites from the Santa Rosa mylonite zone, southern California. J. Struct. Geol. 2, 177-184. 